\title{
FAKTOR-FAKTOR PENYEBAB TERJADINYA HIPERTENSI DI RUMAH SAKIT PTPN BANGKATAN BINJAI TAHUN 2017
}

\author{
Factors Causing The Hipertension at PTPN Bangkatan Hospital in Binjai 2017
}

\author{
Hasan Basri Nasution ${ }^{1}$ \\ ${ }^{1}$ Dosen Akademi Keperawatan Sehat Binjai \\ E-mail: hasanbasrinasution12@yahoo.com
}

\begin{abstract}
Abstrak
Hipertensi adalah suatu keadaan dimana seseorang yang mengalami peningkatan tekanan darah diatas normal yang ditunjukkan oleh angka systolic (bagian atas) dan angka bagian bawah diastolic pada pemeriksaan tensi darah menggunakan alat pengukur (sphygmomanometer). Faktor relatif hipertensi tergantung pada jumlah dan keparahan dari faktor resiko yang dapat dikontrol dan faktor yang tidak dapat dikontrol, itulah yang menjadi alasan peneliti membuat sebuah penelitian dengan judul faktor-faktor penyebab terjadinya hipertensi di RS PTPN II Bangkatan Binjai. Penelitian ini bertujuan untuk mengetahui faktor penyebab terjadinya hipertensi di RS PTPN Bangkatan Binjai. Analisa data menggunakan analisis variate (deskriptif) dengan menggunakan skala pengukuran skala guttman. Untuk masalah karakteristik responden penelitian berdasarkan pekerjaan, mayoritas responden memiliki pekerjaan karyawan PTPN yang berjumlah 9 orang (30\%), berdasarkan keturunan yang tidak dominan begitu dipengaruhi dengan jumlah 18 orang $(60 \%)$, berdasarkan umur yang menunjukkan usia terbanyak yang menderita hipertensi yaitu yang berusia 51-55 tahun yang berjumlah 11 orang (37\%), dan berdasarkan jenis kelamin, laki-laki paling banyak menderita hipertensi yang berjumlah 16 orang (53\%), berdasarkan tingkat pendidikan yang paling banyak yaitu berpendidikan SMA sebanyak 13 orang (43\%), dan berdasarkan asupan garam ada 17 orang (57\%), berdasarkan kebiasaan merokok diperoleh hasil yang sama dengan yang tidak merokok. Jadi, dapat disimpulkan bahwa ada faktor-faktor yang menyebabkan terjadinya penyakit hipertensi. Maka diharapkan bagi responden agar memperbaiki gaya hidup dan menghindari faktor pencetus penyakit hipetensi, dan diharapkan bagi perawat RS PTPN II Bangkatan Binjai juga memberikan promosi kesehatan kepada pasien tentang cara untuk menghindari terjadinya hipertensi, dan diharapkan bagi penulis selanjutnya karya tulis ilmiah ini dapat dijadikan pedoman dan referensi dalam pembuatan karya tulis ilmiah.
\end{abstract}

Kata kunci : Hipertensi, Dystolic, Systolic

\begin{abstract}
Hypertension is a condition in which a person who experiences an increase in blood pressure above normal is indicated by a systolic number (upper part) and a lower diastolic number on a blood pressure examination using a measuring device (sphygmomanometer). The relative factors of hypertension depend on the number and severity of the risk factors that can be controlled and the factors that cannot be controlled, which is the reason the researchers made a study with the names of the causes of hypertension in PT Departure II Bangkat Binjai Hospital. This study aims to determine the causes of hypertension in PTPN Bangkatan Binjai Hospital. Data analysis uses variate analysis (descriptive) using the Guttman scale measurement scale. For the problem of the characteristics of respondents based on occupation, the majority of respondents have jobs of PTPN employees totaling 9 people (30\%), based on offspring who are not dominant so influenced by the number of 18 people $(60 \%)$, based on age which shows the most age who suffer from hypertension aged 51-55 years, amounting to 11 people (37\%), and based on sex, the men suffered the most hypertension, amounting to 16 people $(53 \%)$, based on the highest level of education, namely high school education as many as 13 people $(43 \%)$, and based on salt intake there are 17 people $(57 \%)$, based on smoking habits the same results as those who do not smoke. So, it can be concluded that there are factors that cause hypertension. So it is expected for respondents to improve their lifestyle and avoid the trigger factors of hypotension, and it is expected that nurses in PT Bangkat Binjai Hospital also provide health promotion to patients on ways to avoid hypertension, and it is hoped that later writers can use this scientific paper as a guide and reference in making scientific papers.
\end{abstract}

Keywords: Hypertension, Dystolic, Systolic 


\section{PENDAHULUAN}

Hipertensi salah satu penyakit yang sering disebut sebagai the silent diasease atau penyakit tersembunyi, sebutan tersebut berawal dari banyaknya orang yang tidak sadar sudah mengidap penyakit hipertensi sebelum mereka melakukan pemeriksaan tekanan darah, hipertensi dapat menyerang siapa saja, dari berbagai kelompok umur dan status sosial.

Tekanan darah tinggi sering disebut sebagai pembunuh gelap/ silent killer karena termasuk penyakit yang mematikan. Hipertensi adalah penyakit yang dapat menyerang siapa saja, baik muda maupun tua. Hipertensi merupakan salah satu penyakit yang paling mematikan di dunia. Sebanyak 1 milyar oarng di dunia atau 1 dari 4 orang dewasa menderita penyakit ini. Diperkirakan jumlah penderita hipertensi akan meningkat menjadi 1,6 milyar menjelang tahun 2025 (Dewi, 2013).

Berdasarkan riskasdas 2007 sebagian besar kasus hipertensi di masyarakat belum terdiagnosis hasil riset kesehatan dasar (riskasdas) ahun 2007 oleh badan penelitian dan pengembangkan komkes RI bahkan menunjukkan prevalensi nasional sebanyak 31,7\% (Yusti, 2011).

Kasus hipertensi di beberapa Povinsi di Indonesia sudah melebihi ratarata nasional, dari 33 Provinsi di Indonesia terdapat 8 Provinsi yang kasus penderita hipertensi melebihi rata-rata nasional yaitu : Sulawesi Selatan (27\%), Sumatra Barat (27\%), Jawa Barat (26\%), Jawa Timur (25\%), Sumatra Utara (24\%), Sumatra Selatan (24\%), Riau (23\%), dan Kalimantan Timur (22\%). Sedangkan dalam perbandingan kota di Indonesia kasus hipertensi cenderung tinggi pada daerah urban seperti ; Jabodetabek, Medan, Bandung, Surabaya, dan Makassar yang mencapai 30-34\% (Zamhir, 2006).

Adapun jenis-jenis hipertensi berdasarkan penyebabnya yaitu hipertensi primer dan sekunder, hipertensi primer atau hipertensi esensial adalah peningkatan tekanan darah yang diakibatkan oleh penyebab yang belum jelas diketahui yang biasanya dikaitkan dengan perubahan sistem kardiovaskuler (Jantung-pembuluh darah) yang terkait hormonelektrolit dan berbagai zat lain yang mempengaruhi tekanan darah, Hipertensi sekunder ini dapat disebabkan oleh berbagai gangguan pada organ tubuh, hipertensi sekunder ini dapat disebabkan oleh gangguan ginjal (Gagal ginjal) tumor pada kelenjar adrenal, kelainan pada jantung dan efek samping dari penggunaan obatobatan (Yuda P dan Preitag, 2011).

Dimana penyebab tekanan darah tinggi sebagian besar diketahui namun penelitian telah membuktikan bahwa tekanan darah tinggi berhubungan dengan resistensi insulin atau peningkatan kadar insulin (Hiperinsulinenemia), tekanan darah tinggi dan retensi insulin ini merupakan karakteristik dari sindrom metabolik kelompok abdomen ini yang terjadi dari obesitas peningkatan trigliserida dan peningkatan ADL rendah (Shadine, 2010).

Dari penelitian studi yang dilakukan dunia telah ditemukan bahwa berat badan berhubungan dengan tekanan darah berdasarkan praming heart study sebanyak $75 \%$ dan $65 \%$ kasus hipertensi yang telah terjadi pada pria dan wanita secara langsung dikaitkan dengan berat badan (Yuda P dan Freitag, 2011).

Dari hasil laporan pengamatan laporan RS Bangkatan Binjai selama tahun 2016 ditemukan 781 kasus hipertensi dilanjut usia dan diantaranya memiliki gaya hidup yang tidak sehat diantaranya merokok, suka bergadang, sering mengkonsumsi makanan yang banyak mengandung lemak, kurangnya pengetahuan masyarakat tentang gaya hidup sehat pada penderita hipertensi menyebabkan tingginya kejadian hipertensi.

Berdasarkan survey awal tersebut maka saya tertarik untuk melakukan penelitian tentang "Faktor-Faktor Penyebab Terjadinya Hipertensi Di RS. PTPN II Bangkatan Binjai Tahun 2017 "

\section{METODE}

Jenis penelitian ini adalah deskriptif yaitu peneltian yang menggambarkan Faktor-faktor Penyebab Terjadinya Hipertensi DI RS PTPTN II Bangkatan Binjai. Lokasi penelitian dilakukan di RS.PTPN II Bangkatan Binjai.

Waktu penelitian dimulai dari bulan Januari 2018 sampai April 2018. Sampel dalam penelitian ini sebanyak 30 orang yaitu 
dengan teknik pengambilan sampel menggunkaan accidental sampling. Jadi jumlah populasi dalam penelitian ini sebanyak 30 orang.

\section{HASIL DAN PEMBAHASAN}

Tabel 4.1 Karakteristik Responden Penelitian Berdasarkan Umur Di RS PTPN II Bangkatan Binjai Tahun 2017

\begin{tabular}{cccc}
\hline No & $\begin{array}{c}\text { Umur } \\
\text { (tahun) }\end{array}$ & Jumlah & $\begin{array}{c}\text { Persen- } \\
\text { tase }\end{array}$ \\
\hline 1 & $36-40$ & 3 & $10 \%$ \\
2 & $41-45$ & 4 & $13 \%$ \\
3 & $46-50$ & 5 & $17 \%$ \\
4 & $51-55$ & 11 & $37 \%$ \\
5 & $56-60$ & 7 & $23 \%$ \\
\hline & Jumlah & $\mathbf{3 0}$ & $\mathbf{1 0 0 \%}$ \\
\hline
\end{tabular}

Dari tabel diatas diketahui bahwa dari 30 responden yang berumur 36-40 tahun ada 4 orang atau $13 \%$, pada usia41-45 tahun ada 4 orang atau $13 \%$, pada usia 46 50 tahun ada 5 orang atau $17 \%$, pada usia 51-55 tahun ada 11 orang atau $37 \%$ dan pada usia 56-60 tahun ada sebanyak 6 orang atau $20 \%$.

Tabel 4.2 Karakteristik Responden Penelitian Berdasarkan Jenis Kelamin Di RS PTPN II Bangkatan Binjai Tahun 2017

\begin{tabular}{cccc}
\hline No & $\begin{array}{c}\text { Jenis } \\
\text { kelamin }\end{array}$ & Jumlah & $\begin{array}{c}\text { Persen - } \\
\text { tase }\end{array}$ \\
\hline 1 & Laki-laki & 16 & $53 \%$ \\
2 & Perempuan & 14 & $47 \%$ \\
\hline & Jumlah & $\mathbf{3 0}$ & $\mathbf{1 0 0 \%}$ \\
\hline
\end{tabular}

Dari tabel diatas diketahui bahwa dari 30 responden yang berjenis kelamin laki-laki ada 16 orang atau $53 \%$, dan yang berjenis kelamin perempuan ada 14 orang atau $47 \%$.

Tabel 4.3 Karakteristik Responden Penelitian Berdasarkan Pendidikan Di RS PTPN II Bangkatan Binjai Tahun 2017

\begin{tabular}{cccc}
\hline No & Pendidikan & $\begin{array}{c}\text { Jum- } \\
\text { lah }\end{array}$ & $\begin{array}{c}\text { Persen- } \\
\text { tase }\end{array}$ \\
\hline 1 & SD & 9 & $30 \%$ \\
2 & SMP & 8 & $27 \%$ \\
3 & SMA & 13 & $43 \%$ \\
\hline & Jumlah & $\mathbf{3 0}$ & $\mathbf{1 0 0 \%}$ \\
\hline
\end{tabular}

Dari tabel diatas dapat diketahui bahwa dari 30 responden yang memiliki tingkat pendidikan SD ada 9 orang atau $30 \%$, yang memiliki tingkat pendidikan SMP ada 8 orang atau $27 \%$, dan yang memiliki tingkat pendidikan SMA ada 13 orang atau $43 \%$.

Tabel 4.4 Karakteristik Responden Penelitian Berdasarkan Pekerjaan Di RS PTPN II Bangkatan Binjai Tahun 2017

\begin{tabular}{clcc}
\hline No & Pekerjaan & $\begin{array}{c}\text { Jum- } \\
\text { lah }\end{array}$ & $\begin{array}{c}\text { Persen- } \\
\text { tase }\end{array}$ \\
\hline 1 & Tidak & 4 & $13 \%$ \\
& Bekerja & & \\
2 & Karyawan & 9 & $30 \%$ \\
& PTPN & & \\
3 & Buruh & 8 & $27 \%$ \\
4 & Wiraswasta & 9 & $30 \%$ \\
\hline & Jumlah & $\mathbf{3 0}$ & $\mathbf{1 0 0 \%}$ \\
\hline
\end{tabular}

Dari tabel diatas dapat diketahui bahwa dari 30 responden yang tidak bekerja ada 4 orang atau $13 \%$, yang bekerja sebagai karyawan PTPN ada 9 orang atau 30\%, yang bekerja sebagai buruh ada 8 orang atau $27 \%$, dan yang bekerja sebagai wiraswasta ada 9 orang atau $30 \%$.

\begin{tabular}{|c|c|c|c|}
\hline \multicolumn{2}{|c|}{$\begin{array}{l}\text { Tabel } 4.5 \quad K \\
\text { Responden } \\
\text { Keturunan Di } \\
\text { Binjai Tahun } \\
\text { R }\end{array}$} & $\begin{array}{l}\text { kteristik } \\
\text { asarkan } \\
\text { TPN II }\end{array}$ & $\begin{array}{r}\text { Jawaban } \\
\text { Faktor } \\
\text { Bangkatan }\end{array}$ \\
\hline No & $\begin{array}{c}\text { Faktor } \\
\text { keturunan }\end{array}$ & Jumlah & Persentase \\
\hline 1 & Dominan & 12 & $40 \%$ \\
\hline 2 & $\begin{array}{l}\text { Tidak } \\
\text { Dominan }\end{array}$ & 18 & $60 \%$ \\
\hline & Jumlah & 30 & $100 \%$ \\
\hline
\end{tabular}

Dari tabel diatas dapat dilihat bahwa distribusi jawaban responden berdasarkan faktor keturunan di RS PTPN II Bangkatan Binjai Tahun 2017 maka responden yang 
dominan sebanyak 12 orang ( $40 \%$ ) dan responden yang tidak dominan ada 18 orang $(60 \%)$.

Tabel 4.6 Karakteristik Jawaban Responden Berdasarkan Faktor Usia Di RS PTPN II Bangkatan Binjai Tahun 2017

\begin{tabular}{clcc}
\hline No & $\begin{array}{c}\text { Faktor } \\
\text { Usia }\end{array}$ & Jumlah & Persentase \\
\hline 1 & Dominan & 19 & $63 \%$ \\
2 & Tidak & 11 & $37 \%$ \\
& $\begin{array}{c}\text { Dominan } \\
\text { Jumlah }\end{array}$ & $\mathbf{3 0}$ & $\mathbf{1 0 0 \%}$ \\
\hline
\end{tabular}

Dari tabel diatas dapat dilihat bahwa distribusi jawaban responden berdasarkan faktor usia di RS PTPN II Bangkatan Binjai Tahun 2017 maka responden yang dominan sebanyak 19 orang ( $63 \%$ ) dan responden yang idak dominan ada 11 orang ( $37 \%$ ).

Tabel 4.7 Karakteristik Jawaban Responden Berdasarkan Faktor Asupan Garam Di RS PTPN II Bangkatan Binjai Tahun 2017

\begin{tabular}{clcc}
\hline No & $\begin{array}{c}\text { Fakor } \\
\text { Asupan } \\
\text { Garam }\end{array}$ & Jumlah & Persetase \\
\hline 1 & Dominan & 17 & $57 \%$ \\
2 & Tidak & 13 & $43 \%$ \\
& Dominan & & \\
\hline & Jumlah & $\mathbf{3 0}$ & $\mathbf{1 0 0 \%}$ \\
\hline
\end{tabular}

Dari tabel diatas dapat dilihat bahwa distribusi jawaban responden berdasarkan faktor asupan garam di RS PTPN II Bangkatan Binjai Tahun 2017 maka responden yang dominan sebanyak 17 orang (57\%) dan responden yang tidak dominan ada 13 orang (43\%).

Tabel 4.8 Karakteristik Jawaban Responden Berdasarkan Faktor Merokok Di RS PTPN II Bangkatan Binjai Tahun 2017

\begin{tabular}{cccc}
\hline No & $\begin{array}{c}\text { Faktor } \\
\text { Merokok }\end{array}$ & Jumlah & Persentase \\
1 & $\begin{array}{c}\text { Dominan } \\
\text { Tidak }\end{array}$ & 15 & $50 \%$ \\
2 & 15 & $50 \%$ \\
& Dominan & & \\
\hline & Jumlah & $\mathbf{3 0}$ & $\mathbf{1 0 0 \%}$ \\
\hline
\end{tabular}

Dari tabel diatas dapat dilihat bahwa distribusi jawaban responden berdasarkan faktor merokok di RS PTPN II Bangkatan Binjai Tahun 2017 maka responden yang dominan sebanyak 15 orang $(50 \%)$ dan responden yang tidak dominan ada 15 orang $(50 \%)$.

Tabel 4.9 Karakteristik Jawaban Responden Berdasarkan Faktor Kurang

Olahraga

Di RS PTPN II Bangkatan Binjai Tahun 2017

\begin{tabular}{clcc}
\hline No & $\begin{array}{c}\text { Kurang } \\
\text { Olahraga }\end{array}$ & Jumlah & Persentase \\
\hline 1 & Dominan & 18 & $60 \%$ \\
2 & $\begin{array}{l}\text { Tidak } \\
\text { Dominan }\end{array}$ & 12 & $40 \%$ \\
\hline & Jumlah & $\mathbf{3 0}$ & $\mathbf{1 0 0 \%}$ \\
\hline
\end{tabular}

Dari tabel diatas dapat dilihat bahwa distribusi jawaban responden berdasarkan faktor kurang olahraga di RS PTPN II Bangkatan Binjai Tahun 2017 maka responden yang dominan sebanyak 18 orang $(60 \%)$ dan responden yang tidak dominan sebanyak 12 orang $(40 \%)$.

Dalam penelitian ini yang disajikan sampel adalah penderita hipertensi di RS PTPN II Bangkatan Binjai. Hasil penelitian menunjukkan bahwa :

1. Umur

Dari 30 responden mayoritas responden berumur 51-55 tahun yaitu berjumlah 11 orang atau $37 \%$ dan minoritas responden berumur 36-40 tahun yaitu berjumlah 3 orang atau $10 \%$, hal ini membuktikan bahwa umur sangat berpengaruh terhadap penyebab terjadinya hipertensi.

2. Jenis Kelamin

Dari 30 responden yang berjenis kelamin laki-laki ada 16 orang atau $53 \%$, dan yang berjenis kelamin perempuan ada 14 orang atau $47 \%$, hal ini membuktikan bahwa jenis kelamin dapat mempengaruhi penyebab terjadinya hipertensi.

3. Pendidikan

Dari 30 responden mayoritas responden berpendidikan SMA yaitu sebanyak 13 orang atau $43 \%$ dan minoritas 
responden berpendidikan SMP yaitu sebanyak 8 orang atau $27 \%$, hal ini membuktikan bahwa pendidikan dapat mempengaruhi seseorang terkena hipertensi.

\section{Pekerjaan}

Dari 30 responden yang tidak bekerja ada 4 orang atau 13\%, yang bekerja sebagai karyawan PTPN ada 9 orang atau $30 \%$, yang bekerja sebagai buruh ada 8 orang atau $27 \%$, dan yang bekerja sebagai wiraswasta ada 9 orang atau $30 \%$, hal ini membuktikan bahwa pekerjaan merupakan penyebab terjadinya hipertensi.

Faktor-faktor penyebab terjadinya hipertensi

1) Faktor Keturunan

Responden yang dominan sebanyak 12 orang $(40 \%)$ dan responden yang tidak dominan ada 18 orang $(60 \%)$, karena menurut Susilo 2011 individu dengan orang tua hipertensi memiliki resiko dua kali lebih besar untuk menderita hipertensi.

2) Faktor Usia

Dari 30 responden maka responden yang dominan sebanyak 19 orang (63\%) dan responden yang tidak dominan ada 11 orang (37\%), menurut Freitag 2011 semakin lanjut usia seseorang maka semakin tinggi tekanan darah seseorang karena elastisitas pembuluh darah menurun dan fungsi ginjal sebagai penyeimbang tekanan darah pun menurun.

3) Faktor Asupan Garam

Responden yang dominan sebanyak 17 orang $(57 \%)$ dan responden yang tidak dominan ada 13 orang (43\%), karena menurut Freitag 2011 karena garam dapat meningkatkan jumlah volum garam meningkat, karena didalam garam mengandung natrium dan klor natrium yang beredar dalam darah yang mengakibatkan tekanan darah seseorang bisa meningkat.

4) Faktor Merokok

Responden yang dominan sebanyak 15 orang $(50 \%)$ dan responden yang tidak dominan ada 15 orang (50\%), karena menurut Sitorus 2008 dalam rokok terdapat $\mathrm{CO}$, tar, dan nikotin yang dapat menyebabkan meningkatkan curah jantung seseorang.

5) Faktor Kurang Olahraga

Responden yang dominan sebanyak 18 orang $(60 \%)$ dan responden yang tidak dominan sebanyak 12 orang (40\%), karena menurut Freitag kurangnya aktivitas fisik menaikan risiko tekanan darah tinggi karena bertambahnya risiko untuk menjadi gemuk. Orangorang yang tidak aktif cenderung mempunyai detak jantung lebih cepat dan otot jantung mereka harus bekerja lebih keras pada setiap kontraksi.

\section{KESIMPULAN}

Berdasarkan faktor hasil penelitian di RS PTPN II Bangkatan Binjai Tahun 2017 tentang Faktor - Faktor Penyebab Terjadinya Hipertensi di RS PTPN II Bangkatan Binjai Tahun 2017 maka dapat diambil kesimpulan :

1. Penelitian ini dapat dilakukan dengan baik berkat adanya kerja sama yang baik dari bebagai pihak.

2. Berdasarkan kelompok Usia/Umur dari penelitian yang peneliti lakukan maka banyak menderita hipertensi adalah lansia yang berumur 51-56 tahun yaitu sebanyak 11 orang (37\%).

3. Berdasarkan hasil penelitian responden maka didapatkan hasilkan faktor yang paling dominan terjadinya hipertensi adalah faktor usia sebanyak 19 orang $(63 \%)$.

\section{SARAN}

1. Bagi Responden

Untuk menghindari faktor penyebab yang dapat menyebabkan terjadinya hipertensi.

2. Bagi Puskesmas

Untuk selalu meningkatkan penyuluhan tentang faktor penyebab penyebab Hipertensi.

3. Bagi Peneliti Selanjutnya

Untuk menambah bahan bacaan dan referensi khususnya tentang Hipertensi dan cara pencegahannya. 


\section{DAFTAR PUSTAKA}

Hidayat, A. Aziz, H, 2008. Metode Dan Teknik Analisa Data, Jakarta, Salemba Medika.

Hananta Yuda Putu, 2012. Deteksi Dini Dan Pencegahan 7 Penyakit Penyebab Mati Muda, Yogyakarta, Medpress (Anggota IKAPI).

Notoatmodjo, 2010. Metodologi Penelitian Kesehatan, Jakarta, Rineka Cipta.

Proerawati Atikah, 2010. Obesitas, Yogyakarta, Yuda Medika.

Noviyanti, 2015. Hipertensi, Kenali, Cegah dan Obati, Yogyakarta, Notebook.
Pudiastuti, Ratna Dewi, 2013. PenyakitPenyakit Mematikan, Yogyakarta, Medical Book.

Shadine Mahannad, 2010. Hipertensi, Jakarta Keen Borks.

Sunaryati, Septi Shinta, 2011. 14 Penyakit paling Sering Menyerang dan Sangat Mematikan, Jogjakarta, FlashBooks.

Sitorus Ronald, 2008. Gejala Penyakit Dan Pencegahannya, Bandung, Yrama Widya.

Wulandari Ari, 2010. Cara Jitu Mengatasi Kegemukan, Yogyakarta, Andi Yogyakarta.

http://infohidupsehat.com. 